\title{
Converting alfalfa pasture into annual cropland achieved high productivity and zero loss of soil organic carbon in a semiarid area
}

\author{
Xu-long Zhang ${ }^{1}$, Yangyang Zhao ${ }^{1}$, Wenjuan $\mathrm{Gao}^{2}$, Xin $\mathrm{Song}^{1}$, Xintan Zhang ${ }^{1}$, Xiaoyan \\ $\mathrm{Shi}^{1}$, and Fengmin $\mathrm{Li}^{1}$ \\ ${ }^{1}$ Lanzhou University \\ ${ }^{2}$ Institute of Hydrobiology Chinese Academy of Sciences
}

June 1, 2020

\begin{abstract}
The long-term planting of alfalfa (Medicago sativa L.) gradually reduces the yield and causes severe soil desiccation in semiarid areas. Converting alfalfa pasture into cropland (rotation cropland, RC) is a common way of land use to restore soil moisture. However, it is a challenge for RC to achieve high productivity and maintain high soil organic carbon (SOC) achieved by previous alfalfa. Here, we conducted a nine-year field experiment, with continuous cropland (CC) under plastic film mulching as reference, to evaluate soil moisture restoration, crop productivity, and SOC in RC also under plastic film mulching, in the case of fertilization and non-fertilization, respectively. After the long-term alfalfa pasture was converted to RC, Soil moisture at the upper $2 \mathrm{~m}$ profile, especially the upper $0.6 \mathrm{~m}$, restored rapidly to the levels like the CC. The crop yield and biomass were not significant between RC and CC following the second year of conversion in both fertilization and without fertilization cases. The SOC content in RC without fertilization decreased gradually with the conversion years. However, it had no significant difference in RC with fertilization with the previous alfalfa pasture throughout the nine-year experiment. These findings imply that fertilization allowed the RC under plastic film mulching to keep similar productivity to CC and maintain SOC continuously the same as the previous alfalfa pasture while gradually restore soil moisture. This study provided promising adaptive management for increasing agricultural carbon sequestration and crop productivity in semi-arid Loess Plateau and other similar areas.
\end{abstract}

\section{Hosted file}

Highlights.doc available at https://authorea.com/users/328566/articles/455789-convertingalfalfa-pasture-into-annual-cropland-achieved-high-productivity-and-zero-loss-of-soilorganic-carbon-in-a-semiarid-area

\section{Hosted file}

Manuscript.docx available at https://authorea.com/users/328566/articles/455789-convertingalfalfa-pasture-into-annual-cropland-achieved-high-productivity-and-zero-loss-of-soilorganic-carbon-in-a-semiarid-area

\section{Hosted file}

Figures and Tables.docx available at https://authorea.com/users/328566/articles/455789converting-alfalfa-pasture-into-annual-cropland-achieved-high-productivity-and-zero-

loss-of-soil-organic-carbon-in-a-semiarid-area 

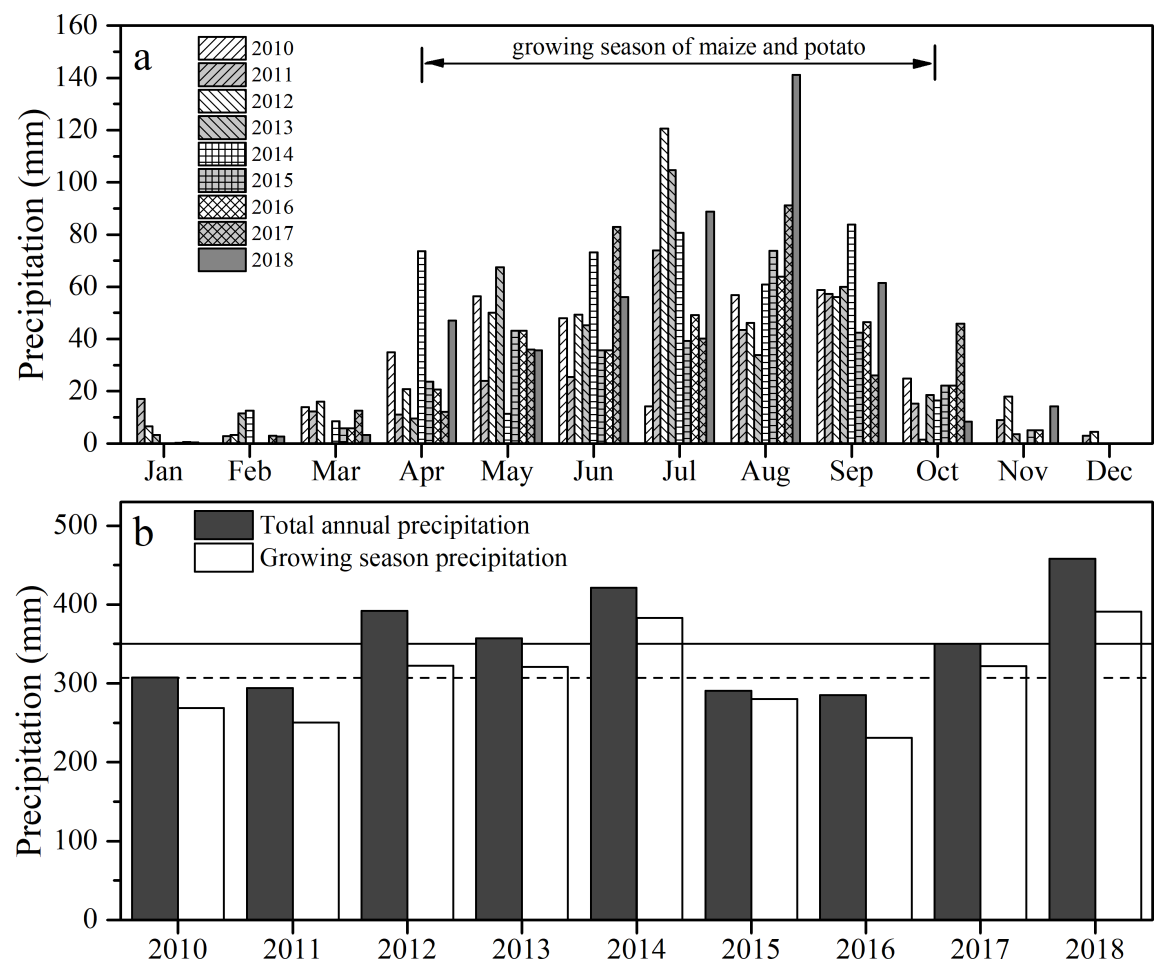

Soil water content (\%)

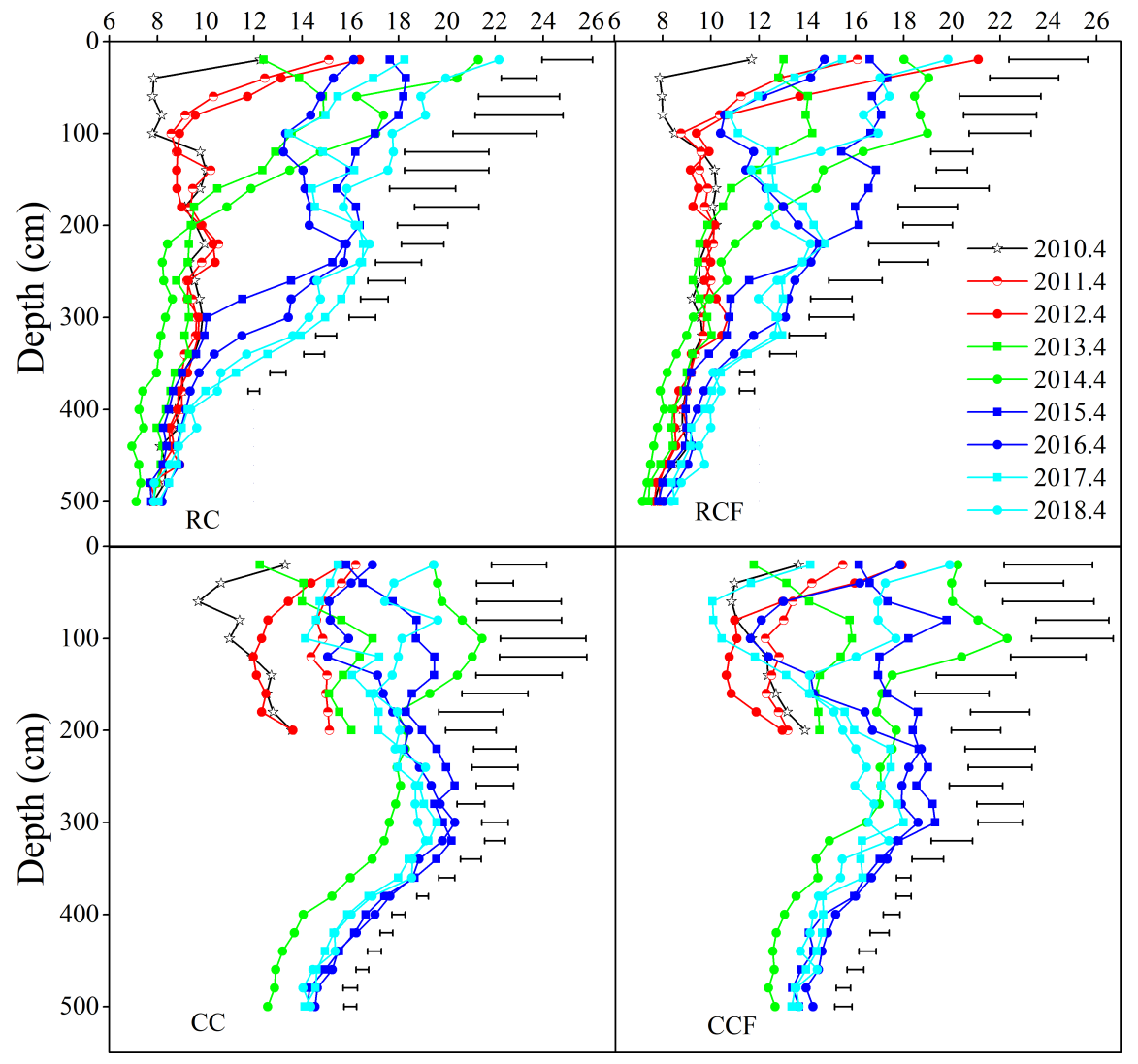



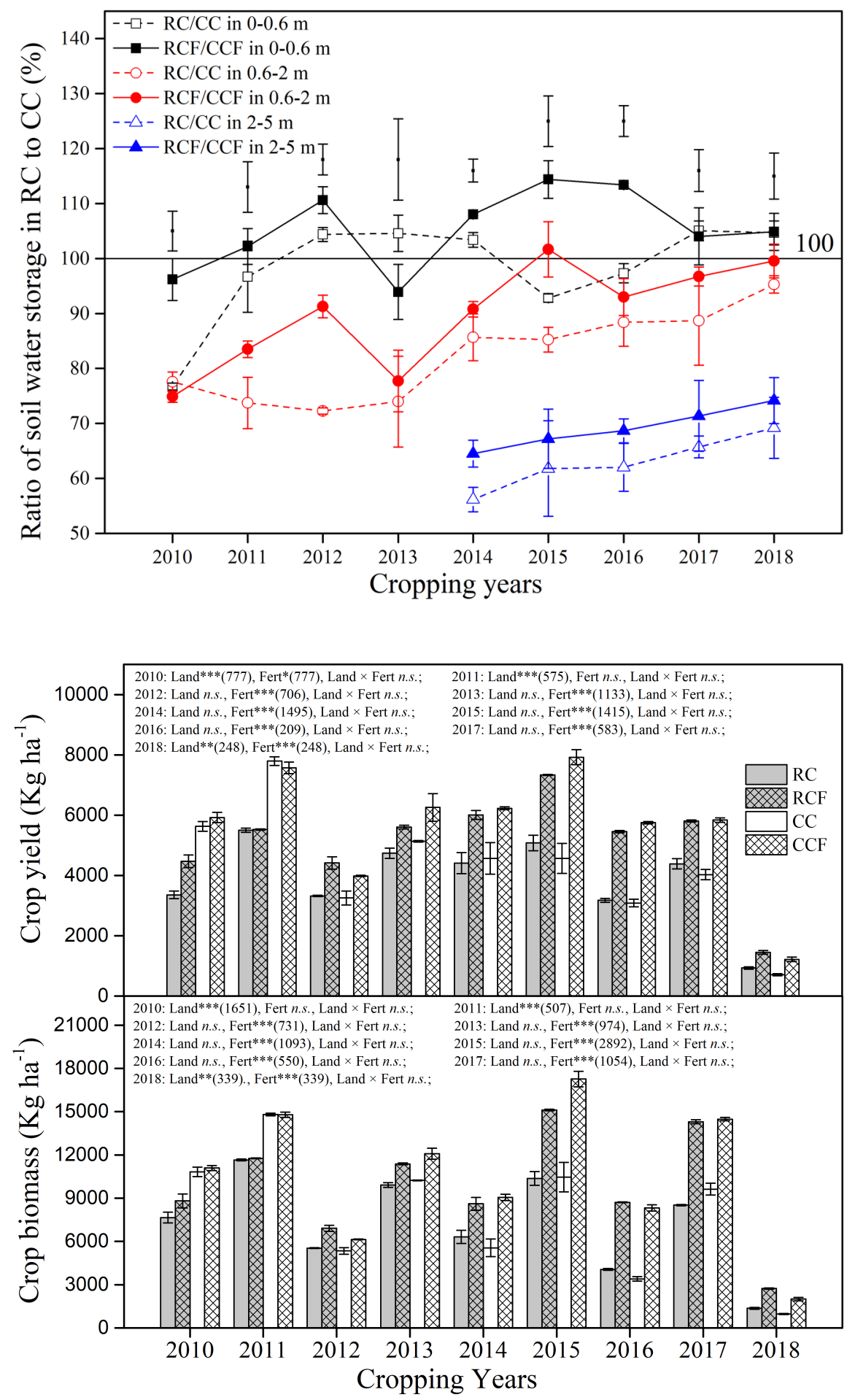

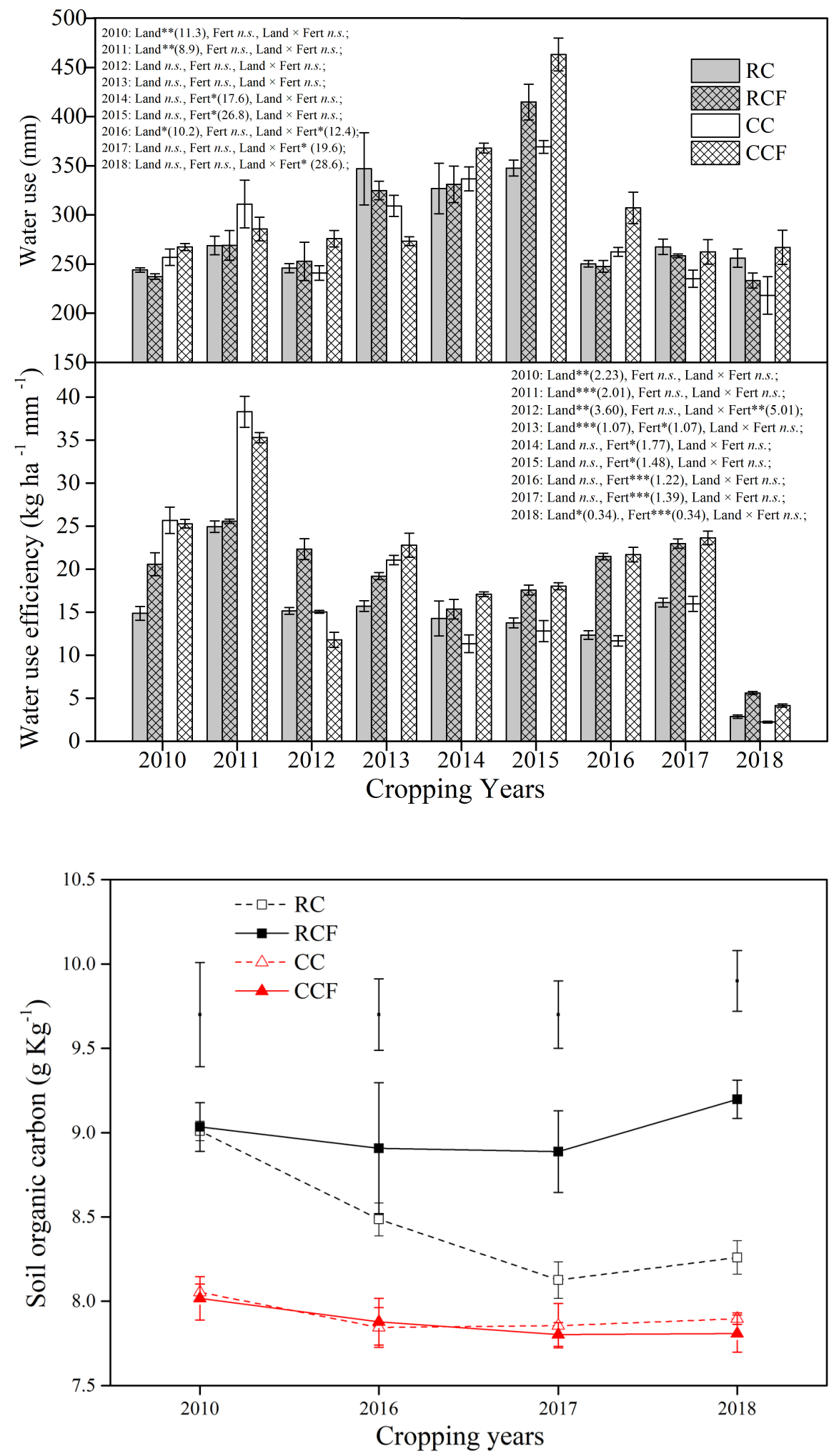


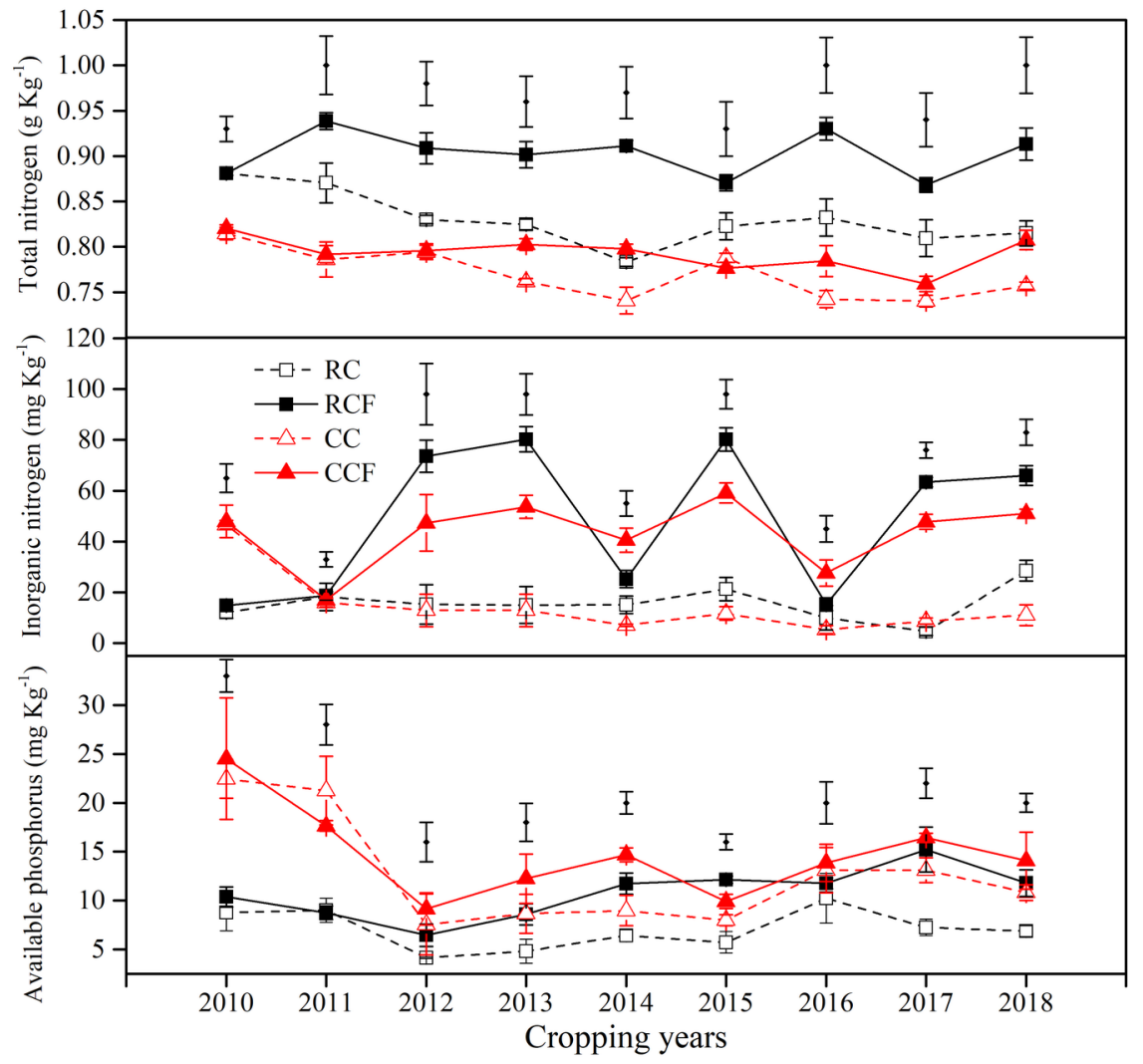

